\title{
TEM Characterization of retained austenite on modified TRIP800 steel
}

Nikolaos Makris ${ }^{1}$, Angelos Kaldellis ${ }^{2}$, Petros Tsakiridis ${ }^{2}$ and George Fourlaris ${ }^{2}$

${ }^{1}$ Lab. of Physical Metallurgy and Center for Electron Microscopy, School of Mining and Metallurgical Engineering, National Technical University of Athens, 15780 Athens, Greece, Athens, Acharnes, Greece, ${ }^{2}$ Lab. of Physical Metallurgy and Center for Electron Microscopy, School of Mining and Metallurgical Engineering, National Technical University of Athens, 15780 Athens, Greece., United States

The steel industry and the transportation sectors strive to adapt to strict environmental targets of $\mathrm{CO} 2$ (production and in-service) emissions, high productivity and novel products ensuring structural integrity, safety and a prolonged life-cycle. The automotive industry utilizes traditionally cold forming for the complex shaping of automobile panels, sometimes sacrificing strength or having to devise complex production routes, leading to complex chemical compositions. Modern research and industry practices such as press hardening or hot stamping take advantage of combining high formability of steel in high temperatures with tailor-made thermal processing routes and strategic alloy additions [1]. It is crucial that the development of the next generation advanced high strength steels have to exhibit micro and nano constituents such as retained austenite, bainitic ferrite, plate martensite and nano-precipitates in order to satisfy today's and future extreme requirements on the mechanical properties [2].

An experimental thermal simulation was carried out on a development grade, cold-rolled annealed steel, having an indicative composition of $0.18 \%$ wt C, $1.33 \%$ wt Mn, $1.67 \%$ wt Si. Austempering was employed, including austenitization at $900 \mathrm{oC}$ for 120 seconds soaking time, followed by isothermal quenching on a molten metal bath at temperature ranges between $250 \mathrm{oC}-450 \mathrm{oC}$ for 120 seconds followed by water quenching at ambient. Standard metallographic preparation techniques and ion milling was employed, with special precautions established for the metastable constituents on thin foil preparation, before examination of the microstructure via Scanning and Transmission electron microscopy, both coupled with EDS microanalysis. Electron diffraction employing parallel or convergent beam modes, bright and dark field imaging and EDS spot microanalysis took place on a TEM Jeol 2100HR unit operating at 200kV. The purpose of this experimental study is to perform a detailed electron microscopical characterization of obtained mixed morphologies, assess and quantify attained volume fractions, spatial distribution characteristics, local chemical compositions and finally to bring about a detailed understanding of solidstate diffusive and displacive phase transformations on the nanoscale. It is envisaged that such added value information could be useful for improved industrial processing of upcoming production technologies in advanced ultra-high strength steels.

This research highlighted the displacive formation of carbide-free bainitic ferrite formation accompanied by the chemical and mechanical stabilization of interlath nanofilm retained austenite populations from diffusive partitioning of carbon at 400oC (Fig. 1). At 300oC, stabilized film-like retained austenite exhibit stacking faults and blocky austenite has partially transformed to high carbon plate martensite (Fig. 2). Hardness Vickers evolution indicates a downward trend upon increasing the isothermal quenching temperature. The confirmation of the presence of nanoscale cementite precipitation on some bainitic ferrite laths suggests either the need of higher additions of graphitizing alloy elements ( $\mathrm{Si}, \mathrm{Al}, \mathrm{P})$ for the $400 \mathrm{oC}$ or longer soaking time at $300 \mathrm{oC}$ to permit carbon diffusion and partition in the adjacent austenite. Key factor for the success story of stabilizing nanofilm retained austenite at $400 \mathrm{oC}$ is the fast displacive phase transformation of bainitic ferrite in combination with sufficient time and temperature for carbon to diffuse. 
The present study offers useful insight into the mechanisms of formation and stabilization of nanostructured retained austenite and could offer valuable advice for improved alloy design and modified modern processing routes for TRIP 800 automotive steels and TRIP assisted advanced ultrahigh strength steels.
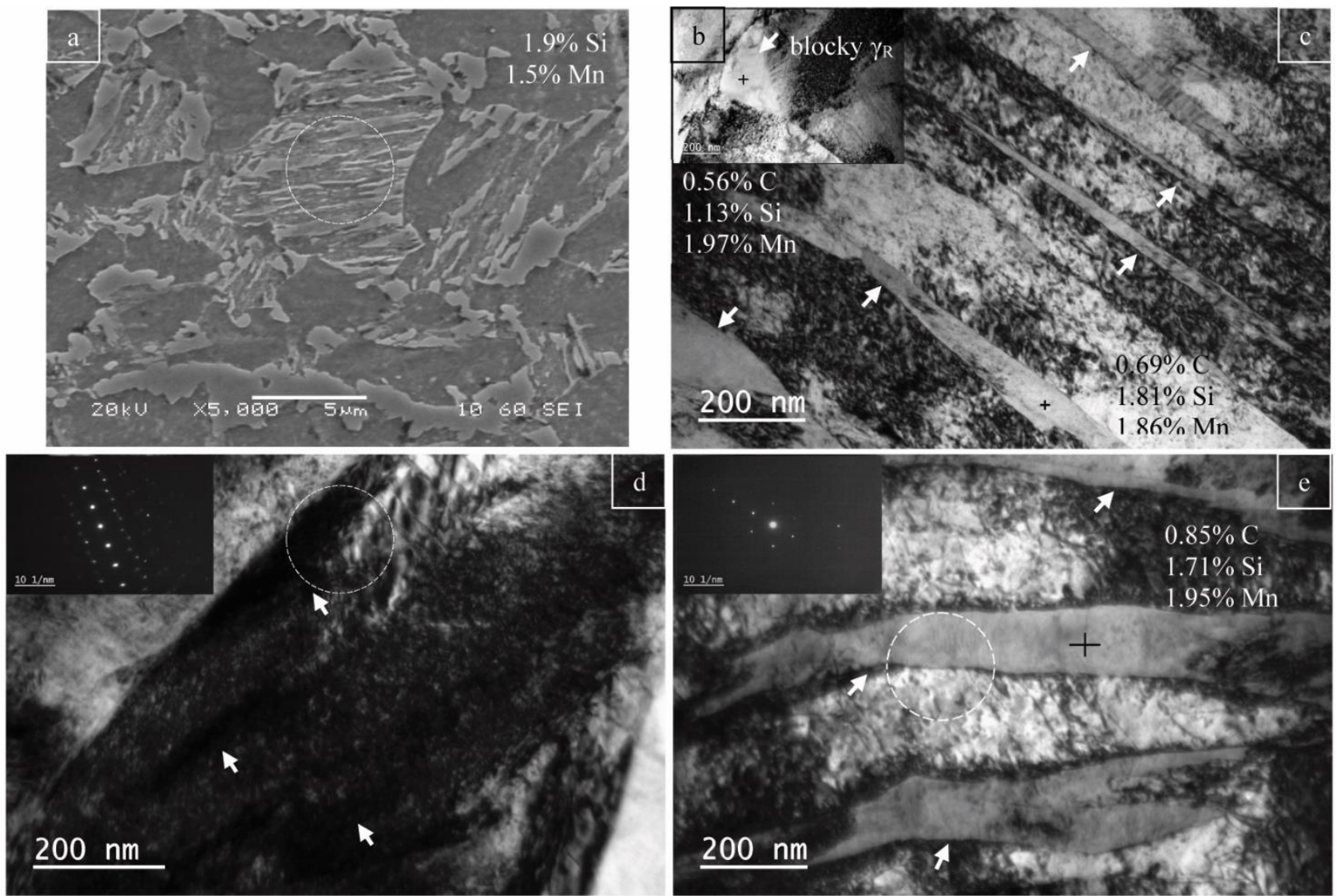

Figure 1. (a) Secondary electron micrograph showing bainitic lath formation and film-like retained austenite (EDS spot microanalysis performed on circled area). (b-e) Bright-field TEM micrographs showing mostly stabilized nanofilm retained austenite (arrowed) by bainitic ferrite growth, accompanied by electron diffraction (performed on the circled area) and EDS spot microanalysis (area marked by cross). All EDS microanalysis are in wt $\%$, with Fe balance and a $+/-0.1 \mathrm{wt} \%$ standard error. All the above micrographs refer to isothermal bainitic quenching at $400 \mathrm{oC}$. 

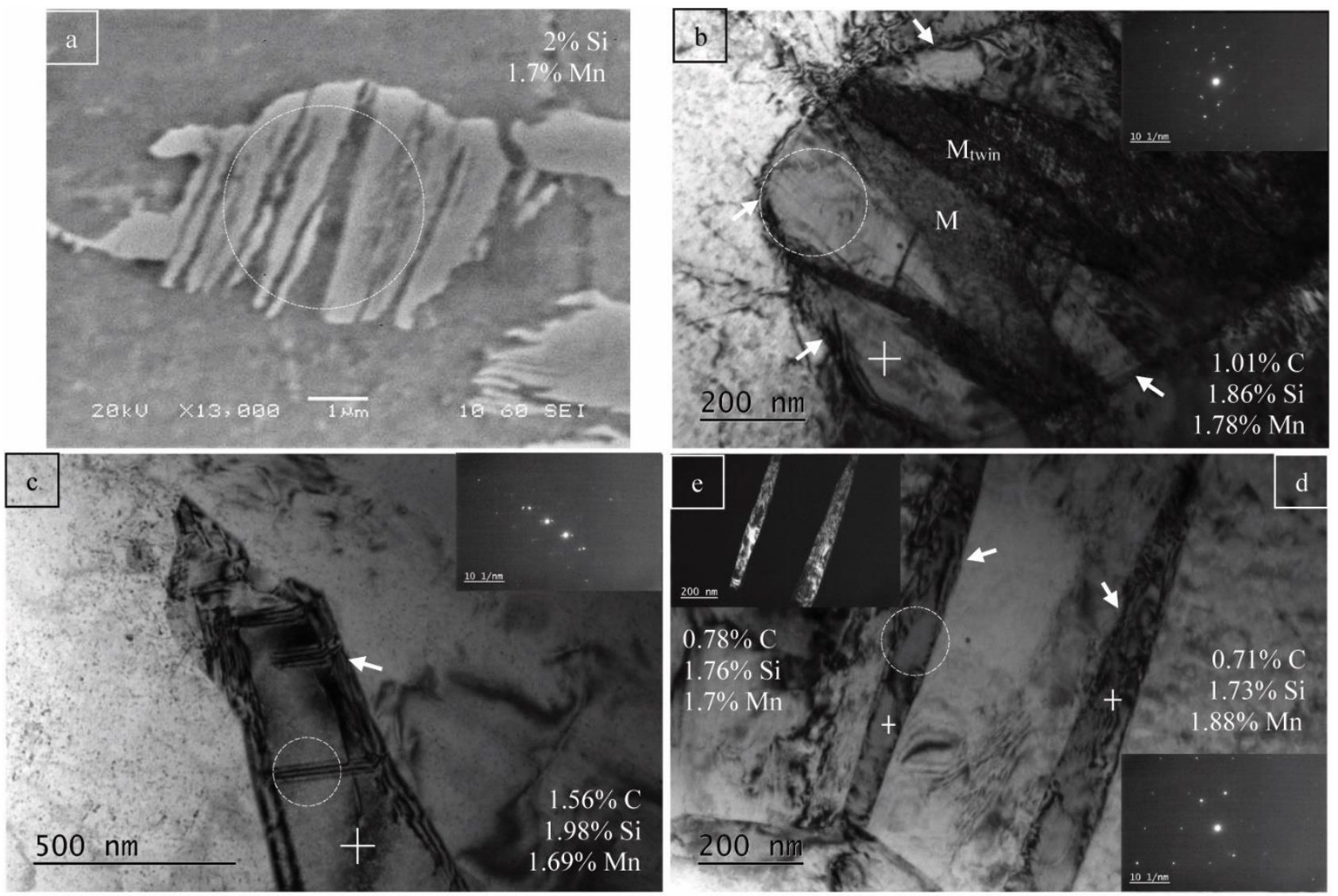

Figure 2. (a) Secondary electron micrograph showing bainitic lath formation and film-like retained austenite (EDS spot microanalysis performed on circled area). (b-d) Bright-field and (e) dark-field (performed on a centered (220) reflection) TEM micrographs showing mostly stabilized nanofilm retained austenite (arrowed) and blocky partially transformed to twinned plate martensite, accompanied by electron diffraction (performed on the circled area) and EDS spot microanalysis (area marked by cross). All EDS microanalysis are in wt $\%$, with Fe balance and a $+/-0.1 \mathrm{wt} \%$ standard error. All the above micrographs refer to isothermal bainitic quenching at $300 \mathrm{oC}$.

\section{References}

[1] Taylor T. et al. (2021) TRIP assisted press hardened steel by the anisothermal bainitic ferrite transformation, Journal of Materials Processing Technology, 289

[2] Makris, N. et al. (2019). Characterization of Complex Retained Austenite on a TRIP800 Automotive Steel. Microscopy and Microanalysis, 25(S2), p. 2614-2615

[3] N.I. Makris is grateful for financial support provided by the Eugenides Foundation, Athens, GR. 